\title{
RIO-BALDO X RIO-BARDO: AS VEREDAS DO NARRADOR ${ }^{1}$
}

\author{
Valéria Castro Fabricius ${ }^{2}$
}

Resumo: Este artigo analisa a função do narrador da obra Grande sertão: Veredas de Guimarães Rosa enfocando dois aspectos principais: a ação narrativa como organizadora, afirmadora e reprodutora do universo regional coletivo, ao mesmo tempo, como reveladora e identificadora da individualidade do próprio narrador. Riobaldo apela à memória para narrar e através de suas reminiscências revela-nos quem somos como também revela a si mesmo. Para tanto, utilizamos como suporte teórico o artigo de Walter Benjamin intitulado "O narrador, observações sobre a obra de Nikolai Leskov" e o de Hanna Arendt denominado "Ação".

Palavras-chave: Grande sertão: Veredas, narrador, memória, coletivo, individual.

\begin{abstract}
This paper analyzes the function of the narrator in the work Grande sertão: veredas by Guimarães Rosa focusing on two main aspects: the narrative action as an organizer, affirming and reproducing the collective regional universe at the same time as revealing and identifying the individuality of the narrator. Riobaldo appeals to memory to narrate and through their reminiscences reveals who we are but also reveals himself. To this end, we used as theoretical support Walter Benjamin's article entitled "O narrador, observações sobre a obra de Nikolai Leskov" and that of Hanna Arendt called "Ação".
\end{abstract}

Keywords: Grande sertão: Veredas, narrator, memory, collective, individual.

\footnotetext{
${ }^{1}$ Uma primeira versão deste trabalho foi publicada nos Anais do VI Simpósio de Literatura, Comparatismo e Crítica Social, no Dossiê n. 14 da Revista Literatura e Autoritarismo.

${ }^{2}$ Doutoranda em Estudos Literários pela Universidade Federal de Santa Maria, UFSM. Bolsista Capes. Integrante da linha de pesquisa "Literatura, Comparatismo e Crítica Social" e do grupo de estudos "Literatura e Autoritarismo", sob orientação da professora Dra. Rosani Ketzer Umbach. E-mail: valcastrofab@yahoo.com.br
} 


\section{Introdução}

Este trabalho pretende realizar um estudo acerca da categoria do narrador na obra "Grande sertão: Veredas" de Guimarães Rosa. Para tanto, tomaremos como referência teórica o texto de Hannah Arendt intitulado "Ação" (2005) e o de Walter Benjamin, "O narrador, observações sobre a obra de Nikolai Leskov" (1983). Nossa proposta de trabalho parte do entrecruzamento das abordagens dos dois teóricos, analisando-as sob a perspectiva do narrador, mais especificamente, a função da narrativa de Riobaldo. Entendemos que sua elocução pode ser analisada sob dois aspectos: o da afirmação e o da especulação.

Primeiro, tomando as prerrogativas de Benjamin, observamos que 0 discurso do ex-jagunço expõe uma leitura de mundo que resgata conhecimentos assimilados ao longo do tempo e de sua experiência, por isso, reflete valores coletivos. Nessa perspectiva, ele se porta como o narrador que domina tais verdades tem, portanto, autoridade para narrá-las e, consequentemente, a responsabilidade de perpetuá-las. Fazendo isso, aproxima-se do narrador primitivo proposto por Benjamim sintetizado nas imagens do artesão e do marinheiro. Independente da figura que se eleja, a fala deles é responsável por identificar, expor e fixar valores. Eles apresentam quem somos.

Simultaneamente, o relato de ex-chefe de bando possui espaços discursivos nos quais prevalecem questionamentos. Sua locução, destinada a um ouvinte silencioso, estabelece um diálogo implícito-explícito permeado por tais indagações. Essas se referem menos ao entendimento das coisas factuais do mundo e mais à ordem individual, do vivenciar. Elas buscam responder à pergunta sugerida por Arendt: quem sou?

Assim, acreditamos ser possível abordar a função da ação narrativa de Riobaldo nessa dupla perspectiva: um relato em que o narrador apropria-se de autoridade para asseverar e, ao mesmo tempo, assume sua relatividade para indagar. Rio-bardo ${ }^{3}$ afirma através do resgate de sua ação no mundo; Riobaldo pergunta na busca da apreensão de seu experienciar o mundo.

\footnotetext{
${ }^{3}$ A adoção do termo Rio bardo foi instituída, considerando uma composição partindo do nome original da personagem, mas também, visando explorá-la, posteriormente, em seu sentido semântico. Bardo como trovador, catador popular, narrador de feitos.
} 


\section{Narrar é muito perigoso...}

A instância narrativa destinada à locução foi e ainda é intensamente estudada, tanto por sua importância, como por suas múltiplas possibilidades de composição. Não pretendemos nesse estudo aprofundá-la visto que esse não é nosso propósito. Nesse contexto, a abordamos em sua perspectiva tradicional. Portanto a narração de Riobaldo será enfocada como relato em primeira pessoa.

A partir das referências ao ponto de vista, podemos aproximá-lo do narrador qualificado por Benjamim. Para o estudioso alemão, uma das grandes virtudes dele é promover a troca de experiências, o intercâmbio o qual "está em vias de extinção"(1983, p.197). Seu ensaio data de 1936, vinte anos depois,publica-se Grande sertão: Veredas obra que traz a lume um dos grandes personagens-narradores da literatura. Riobaldo, dotado de singular eloquência, cria na narração uma trama em que os relatos de vivência resultam em de troca de experiência: o saber compartilhado. Através de atos e palavras ele insere-se e insere-nos no mundo.

\section{Rio-bardo: o narrador no meio do redemoinho.}

$\mathrm{Na}$ obra, o personagem central diante de um estrangeiro, empreende uma grande aventura, explicar-Ihe as vicissitudes do sertão. Espaço impar que prescinde de compreensão particular. Para fazê-lo, elege como estratégia a narração de sua própria história.Para tanto, necessita organizá-la de maneira apreensível, colocando-a em perspectiva. Tal intento representa o núcleo central da obra, o percurso que abarca sua infância, maturidade e velhice. Por sabê-la resultado de um complexo emaranhado de fios, precisa recorrer a vivências outras, experiências individuais que se imbricaram com a sua, personagens que remontam esse viver coletivo no qual Riobaldo está inserido. Para ele "a vida é mutirão de todos, por todos remexida e temperada" (Rosa, 2001, p.477).

Desse imenso caldeirão emergem várias outras pequenas narrativas subjacentes que envolvem personagens ligados a sua história. Riobaldo intercala-asno eixo principal da narração para, de forma próxima à parábola, explicitar o sentido que almeja alcançar. É o que ocorre, por exemplo, quando se refere à história dos filhos de Aleixo "três meninos e uma menina - todos 
cegados" (Rosa, 2001,p.28). O narrador menciona-os para ilustrar os ensinamentos de seu compadre Quelemém,espécie de arauto a orientá-lo no campo das coisas misteriosas. Seguindo sua lógica, eles teriam ficado cegos como punição ao pai:"Se sendo castigo, que culpa das hajas do Aleixo aqueles meninozinhos tinham?" (Rosa, 2001, p.28).

Há nesse trecho três níveis de experiência permeados. Aquela assimilada por Riobaldo nas conversas com seu grande mestre, "meu compadre Quelemém".Há o reconhecimento desse ensino por parte do narrador ao constatá-lo concretizado em seu universo de vivências, e ainda, o intercâmbio deles ao relatá-lo ao viajante.Tal passagem é emblemática da estratégia narrativa adotada por Riobaldo. Nela evidenciam-se, recorrentemente, processos de apropriação, vivência e troca de saberes. Mais do que isso,o ex-jagunço absorve o sentido amplo dessas verdades sintetizando-as e, através da sua perspectiva, de seu olhar e voz, tece conclusões. Finaliza o episódio de Aleixo, asseverando "vem o pão, vem a mão, vem o são, vem o cão" (Rosa, 2001,p. 28).

Benjamim, em seu artigo, ressalta que a crise da narrativa reside também no fato de que as experiências não conseguem mais se converter em situações narráveis decorrente da falta de vitalidade e de sentido de que as mesmas padecem. Riobaldo é o narrador que inverte essas prerrogativas, pois reconhece sentido no que vivenciou, de tal forma que as organiza à maneira de narração para perpetuá-las. O recurso de síntese dessas experiências é um ponto importante em sua estratégia. Assemelha-se ao conselho. Não o é, categoricamente, porque o narrador não ordena explicitamente, antes, lança-a como verdade particular, respaldada pela força da experiência. Não vaticina, mas orienta. Difunde-a para que o ouvinte se aproprie dela ou não. Aceitando-a atribua, ele mesmo, seu novo sentido e valor: "remexer vivo o que vim dizendo. Porque não narrei nada à toa: só apontação principal, ao que crer posso. Não esperdiço palavras. O senhor pense o senhor ache. O senhor ponha enredo." (Rosa, 2001,p.325).

A expressão "remexer vivo o que vim dizendo" revela-nos duas importantes ações desse contador: o lembrar e o refletir. O apelo à memória e a tentativa de compreender aquilo que dela emana, confere-lhe experiência e autoridade para narrar. Atributos essenciais do narrador benjaminiano. 
Raras vezes dá-se conta de que a relação ingênua entre ouvinte e narrador é dominada pelo interesse em reter a coisa narrada. O ponto chave para o ouvinte desarmado é garantir a possibilidade de reprodução. A memória é a capacidade épica por excelência. (Benjamin,1983, p. 66).

Para Benjamin (1983) à narrativa interessa oportunizar que a memória exerça seu papel, o de ser a origem das recordações. O princípio mnemônico é responsável por fundar a tradição do relato transmitido de geração a geração, segundo o filósofo a reminiscência "inclui todas as verdade da forma épica. Entre elas encontra-se em primeiro lugar a encarnada pelo narrador. Ela tece a rede que em última instância todas as histórias constituem entre si" (1983, p. 211).

O discurso apoiado na força da vivência, amparado pelo resgate da memória e habilitado à reprodução, adquire potência de conselho. Esse só será acatado pelo ouvinte, se atribuir ao sujeito da elocução, credibilidade, se reconhecer nele a voz da sabedoria. Para o teórico alemão "o conselho entretecido na vida vivida é sabedoria" (Benjamin, 1983,p. 59). Como diz Riobaldo "Confiança - o senhor sabe -não se tira das coisas feitas ou perfeitas: ela rodeia é o quente da pessoa" (Rosa, 2001, p. 74)

Essa foi adquirida através de um longo percurso de tempo e de vivências. Tal qual o marinheiro, Riobaldo forjou-se através da ação. Ele lançou-se às aventuras de seu tempo, correu riscos, deu-se ao embate. Não o fez só. Na condição de jagunço conheceu os grandes heróis de sua época e meio, lutou com eles e por eles. Os príncipes do sertão, com seus feitos, suas incontestáveis verdades incorporaram-se ao "ser" Riobaldo, determinaram seu viver, um viver já superado. Esse privilégio de experiência dota-o de uma singularidade. Reconhecer-se como caudatário de um mundo em extinção. Tal consciência confere-lhe o estatuto de guardião desse passado histórico e lendário, esvanecido no presente. O velho fazendeiro sabe que os grandes personagens que povoam sua lembrança têm merecimento para se perpetuar. Ao encontrar um estrangeiro que desconhece o sertão e suas leis, o narrador reconhece nele um ouvinte apropriado, capaz de compreender a dimensão maior do que relata e sujeito ao estranhamento que desperta o interesse pelo 
narrado. "Três dias" reitera o ex-chefe de bando, determina assim, o tempo da estadia e instaura o tempo da narração.

Ao ouvir tiros ao longe reconhece o mote que instiga o interesse do doutor. "Nonada. Tiros que o senhor ouviu foram de briga de homem, não" (Rosa, 2011, p.33). Dá início ao relato, de armas, guerras e feitos, tanto seus quanto daqueles que impregnaram esse sertão que retrata e relata. Tal qual os bardos "poetas e cantores que empregavam o talento para elogiar os príncipes e reis, celebrar feitos de guerra e conservar a memória das linhagens" (Moisés,1974,p.57). Riobaldo conta, lembra, afirma, pergunta, especula, duvida. Organiza a narração sobre uma cambiante estrutura temporal e causal. Ele se permite digressões, tempera-a com sua loquacidade e colore-a com episódios e personagens que ilustram suas verdades e veredas. Resgata um tempo, um espaço, um modelo de vida: o sertão e a jagunçagem. Depositário de uma herança simbólica propagada pela linguagem atribui-Ihe sentido. Um sentido estranho ao estrangeiro, porque afirma valores milenares: honra, lealdade e justiça sob uma perspectiva única, apreendida apenas em seu contexto, o sertão. Território insulado, à mercê da civilidade urbana. Espaço próprio com sua gente, suas leis. Para explicitá-lo ao forasteiro elogia seus heróis, celebra suas façanhas, conserva a memória coletiva. Rio-bardo colocase no meio do redemoinho da história e das estórias, numa franca atitude de resistência ante ao apagamento da identidade individual e social. Lembra quem fomos.

Eu queria decifrar as coisas que são importantes. $E$ estou contando não é uma vida de sertanejo, seja se for jagunço, mas a matéria vertente (...) Assim, é como conto as coisas que foram passado para mim com mais pertença. Vou lhe falar. Lhe falo do sertão. (Rosa,2001,p.1160).

Em seu artigo, Benjamin (1983) propõe uma análise acerca da função do narrador, em que pressagia o fim do romance, atribuindo à crise do narrar uma de suas causas primordiais. Seu estudo vaticinou o que hoje vivenciamos. A dificuldade de apreensão das próprias vivências. O narrador por excelência dominava a narração porque compreendia a estrutura explicita e implícita das regras do mundo. Um mundo relativamente dimensionado que conseguia, ainda que de forma frágil, estabelecer verdades porque essas tinham, ou 
pareciam ter caráter de perenidade. "Grande Sertão: veredas", lançado vinte anos depois, propõe reiterar suas assertivas. A obra tem sua estrutura alicerçada na figura do narrador. Todo o restante que se depreende dela advém da elocução de Riobaldo. Ele trafega pelo externo, pelo social, pelo histórico, pelo cultural para fixar valores, prescinde da memória. Ao mesmo tempo, em sua incursão individual, revela-nos que as regras do mundo precisam ser apropriadas pelo indivíduo. Esse ato tem o poder de redimensionar as verdades, relativizando-as. Viver é perigoso porque resulta desse inerente intercâmbio: experienciar individualmente o que o mundo nos apresenta como verdade. Equacionar essas duas dimensões resulta em experiência.

Guimarães Rosa e Walter Benjamim partilham da mesma inquietante verdade. Eles detectaram e pressagiaram uma crise aguda do viver. A queda da aura e a desorientação causada pela relativização das verdades geraram na literatura a crise da narração, dos gêneros; na vida, a crise do apreender. Ambos reportam-se ao passado, Benjamin referindo-se a ele como esteio dos grandes modelos narrativos; Guimarães como o suporte de referencialidade onde se cristalizaram nossas verdades. Ambos perceberam um grande perigo a nos rondar, talvez maior do que aquele que conheciam, acenavam para 0 advento de um tempo no qual viveríamos a incapacidade de configurar verdades. Se para eles a tônica do viver era sua dimensão do perigo, para nós, talvez seja a generalização da dúvida, pois hoje, mais do que nunca..."viver éetcétera." (Rosa, 2001, p.110).

\section{Rio-baldo: a travessia do narrador.}

Arendt em seu artigo "A ação"(2005) tece um estreito vínculo entre ato e linguagem, ação e discurso. Parte da premissa de que para nos inserir e individualizar no mundo precisamos agir. Além disso, é imprescindível por-nos em discurso, para a filósofa "o discurso corresponde ao fato da distinção e é a efetivação da condição humana da pluralidade" (Arendt, 2005 p. 191). Segundo a estudiosaele é o ato revelador de quem somos. Nesse sentido, a narração de Riobaldo pode representar uma ação de identificação dele ante ao estrangeiro e, simultaneamente, de auto-identificação. Esta revelação dupla ocorre porque,podemos detectar dois níveis inter-relacionados em seu relato. $O$ 
externo, espaço da ação onde se reflete o mundo, e o interno, espaço individual onde a indagação espelha as incertezas do eu.

No seu diálogo com o visitante o ex-chefe de bando conta sua vida, pontuando-o de questionamentos. Esses se referem à tentativa de apreensão e valoração de algumas de suas experiências. Pelas indagações que propõe, Riobaldo revela-nos que não é capaz de dimensionar claramente eventos cruciais de sua existência. Ele reconhece que ao longo de sua trajetória vários acontecimentos permanecem obscuros: o possível pacto, o amor/fascínio por Diadorim, suas multifacetas, sua duvidosa coragem. Esses são pontos nebulosos e também fundamentais na constituição do seu eu, por isso contaminam toda a narração. Ao pretender narrar sua vida e suas lutas o fazendeiro sabia que, ao fazê-lo, confrontaria suas sombras e veredas. Sua identidade estava além dos atos, residia também na capacidade de atribuir-lhes sentido, portanto, não o faria sem defrontá-los. Seu contar-lembrar abriu-se como possibilidade de compreender.

Não devia estar relembrando isto, contando assim o sombrio das coisas. Lenga-lenga! Não devia de. O senhor é de fora, meu amigo mas meu estranho. Mas, talvez por isto mesmo. Falar com o estranho assim, que bem ouve e logo longe se vai embora, é um segundo proveito: faz do jeito que eu falasse mais comigo mesmo. Mire e veja: o que é ruim, dentro da gente, agente perverte sempre por arredar mais de si. Para isso é que o muito se fala? (Rosa, 2001,p.55).

Assim, sua elocução, não se limita aos acontecimentos, excede-os, tenta capturá-los em sua essência, em seu sentido maior e mais profundo. $O$ narrador rastreia suas emoções, expondo não o que são agora, mas como eram no momento em que ocorreram. Nesse processo, ele as revive para tentar atribuir-Ihes sentido.

[...] lembrança da vida da gente se guarda em trechos diversos, cada um com seu signo e sentimento, uns com os outros (...) de cada vivimento que eu real tive, de alegria forte ou pesar, cada vez daquela hoje vejo, que eu era como se fosse diferente pessoa. Sucedido, desgovernado" (Rosa, 2001,p.115).

$\mathrm{Na}$ juventude Riobaldo deu-se ao embate com o mundo, na velhice precisou dar-se ao embate com o eu, fê-lo apelando à memória e ao discurso. 
Porém, ambos não eram suficientes, era necessário munir-se de conhecimento para aceitar, entender e interpretar o vivido. O velho fazendeiro sabia disso. Sua opção de contar sua trajetória ao estrangeiro também reveste desse duplo intento. Sabia-o estranho, principalmente, reconhecia nele o homem viajado, doutor que, vindo de outras terras, dominando outras verdades, poderia, por isso, auxiliá-lo na elucidação do que ele, por si só não podia. Nessa perspectiva, o agora Riobaldo-artesão encontra-se com o doutor-marinheiro, o diálogo estabelece a permuta por excelência. Experiência do que vem de fora e experiência do que reside no dentro.

Solto, por sí, cidadão é que não tem diabo nenhum. (...) 0 senhor aprova? Me declare tudo, franco - é alta mercê que me faz: e pedir posso, encarecido. (...) Mas não diga que o senhor assisado e instruído, que acredita na pessoa dele?! Não? Lhe agradeço. Sua alta opinião compõe minha valia. Já sabia, esperava por ela" (Rosa, 2001, p. 26).

Tal conversa nos é acessada apenas de forma unilateral, sabemos que o estrangeiro fala, pois Riobaldo menciona suas ações, responde a perguntas que não nos são reproduzidas, uma espécie de "monodiálogo": "Amável o senhor me ouviu. Minha ideia confirmou: que o diabo não existe. Pois não? 0 senhor é um homem soberano, circunspecto. Amigo somos" (Rosa, 2001, p.624).

A busca por entendimento não é particularidade apenas dessa ocasião. Possuir o entendimento das coisas é um dos grandes desejos de Riobaldo.

Eu sei que isto que estou lhe dizendo é dificultoso, muito entrançado. Mas o senhor vai avante. Invejo é a instrução que o senhor tem. Eu queria decifrar as coisas que são importantes (...) Queria entender do medo e da coragem e da gã que empurra agente para fazer tantos atos, dar corpo ao suceder (Rosa, 2001,p. 75).

Embora se reconheça limitado, sabe-se também capaz de atribuir sentido as coisas da vida: "Eu quase nada não sei, mas desconfio de muita coisa. O senhor concedendo, eu digo: pra pensar longe sou cão-mestre - 0 senhor solte em minha frente uma ideia ligeira e eu rastreio essa por fundo de todos os matos" (Rosa,2001, p.31). 
Entretanto, nem a narração e o conhecimento de Riobaldo tampouco pouco a instrução do que vem de fora dissipam as dúvidas do fazendeiro. Ele aproxima-se dos momentos graves de sua vida, menciona-os, rodeia-os, mas é incapaz trazê-los à elocução. Constrói o espaço do subtendido, do interdito.

E eu não tinha medo mais. Eu? O sério pontual é isto, o senhor me escute, me escute mais do que eu estou dizendo; e escute desarmado. O sério é isto, da estória toda - por isto foi que a história Ihe contei - eu não sentia nada. Só uma transformação, pesável. Muita coisa importante falta nome (Rosa, 2001,p.125).

Nessa passagem Riobaldo revela-nos que as grandes verdades são inapreensíveis em sua totalidade, que os grandes momentos da vida podem transcorrer no âmbito interno, do indizível. Por isso sua narração está repleta de especulações, elas representam mais 0 imensurável do que 0 incompreensível. Riobaldo mostra-nos que subjaz à matéria vertente outra de natureza mais sutil e, de certa forma, inalcançável. Seu amor por Diadorim, a existência do diabo, sua incerta coragem balizam seu viver, dão passagem às veredas, arrastam-no aos escuros do homem porque estão além de seu conhecimento ou de outro qualquer, pertencem a outra ordem, do imensurável.

Arendt afirma que "só podemos saber quem um homem foi se conhecermos a história da qual ele é o herói - em outras palavras sua biografia" (Arendt, 2005, p. 199). Através de sua narração Riobaldo deu-se a conhecer, apresentou sua biografia. Ele não se eximiu da tarefa de narrá-la completa. Os espaços que permanecem vazios, baldios, não resultam de uma incapacidade sua, de uma covardia, mas respondem pela essência do viver. Reconhecer essa potência e dobrar-se a ela talvez tenha sido sua maior coragem. A filósofa afirma que

[...] a conotação de coragem que hoje reputamos qualidade indispensável a um herói (...) já está de fato presente na mera disposição de agir e falar, de inserir-se no mundo e começar uma história própria. (...) o próprio ato do homem que abandona seu esconderijo para mostrar quem é, para revelar e exibir sua individualidade já denota coragem (...) essa coragem original (...) não é menor- pode ser até maior- quando o herói é um covarde" (Arendt, 2005,p. 199). 
Um dos temas principais da narração de Riobaldo é a afirmação/negação de sua coragem. Uma coragem entendida no plano da ação. No plano da narração Riobaldo não se furta de reconhecer seus medos, nela é que desvela suas limitações íntimas, as dúvidas que assombram seu viver. Assumi-las outorga-lhe o estatuto de individuo que, apesar de não dominar o mundo e o saber, tem autonomia e coragem para enfrentá-lo e narrá-lo.

Assim Rio-baldo, como instância narrativa, empreende uma travessia, uma baldeação e a alcança, aporta do outro lado do rio. Perscruta seu mundo interno, identifica seus temores, seus escuros e os relata. Se confrontá-los não foi o suficiente para dissolvê-los, é porque tal empresa está além da própria travessia. Segundo o pesquisador Guinzburg livros como "Grande sertão: Veredas" não estão estruturados em termos de um dualismo organizado, com ordem e desordem bem definidas; eles não propõem imagens nítidas da existência, nem convertem o estranho em familiar" (2012). A obra, portanto, também abre espaço para o indefinido, pois como assevera o estudioso Grande Sertão: Veredas está entre os textos em que as "palavras não são transparentes, eles propõem que a linguagem tem que lidar com 0 incomunicável (...) eles insistem em que é necessário narrar até mesmo o que nunca se compreenderá"(Ginzburg, 2012,p. 130).

\section{No levantar do dia. Auroras.}

A narração empreendida por Riobaldo possui duplo caráter: o resgate e fixação de tipos, de um contexto e de um tempo, o estar no mundo. Simultaneamente, é um discurso de imersão na vivência individual, das emoções, o experienciar o mundo. Sua elocução transita por essas duas veredas que são, na verdade, inerentes ao próprio viver. A narrativa que resulta desse imbricamento cumpre também duas funções: revela-nos "quem somos" e desvela "quem sou". Assim, podemos colocá-la nas perspectivas propostas por Benjamin e Arendt cruzando-as.

Para Arendt a "qualidade reveladora do discurso e da ação vem à tona quando as pessoas estão com outras (...) só é possível na esfera pública" (Arendt, 2005, p.193). Para a filósofa, mostrar-se ao mundo associando seu agir ao seu falar é um ato de individualização e de revelação. Para Benjamin, a 
narrativa "não pretende transmitir o puro 'em si' da coisa (...) mergulha a coisa na vida de quem relata a fim de extraí-la outra vez dela. É assim que adere à narrativa a marca de quem narra" (Benjamin,1983 p. 63). Ambos autores ressaltam a importância da apropriação individual da experiência e de sua verbalização sob essa perspectiva pessoal que confere à narração uma organização e exposição no plano da linguagem, única e particular. O narrador de "Grande sertão: Veredas" cumpre esse intento.

Rio-bardo coloca-se em meio ao redemoinho da história-estória sem, contudo, deixar-se arrastar, ele resiste estabelecendo a ordem, dando direção e sentido ao narrar. Rio-baldo imerge nas águas sombrias de seu rio-memóriadúvida e atravessa-o, confronta seus temores, expõe suas incertezas e emerge, na outra margem. Essas duas ações prescindem de elocução a qual, de alguma forma, é sempre reveladora - identificadora tanto do eu para os outros como de mim para mim. Assim, o contar possui, em essência, uma função catártica, tanto quanto lembrar resguarda uma essência reveladora. Riobaldo finaliza sua história afirmando "e me cerro (...) conto o que fui e vi", o fazendeiro, para fazê-lo, precisou atribuir sentido ao seu ser dentro do seu viver. Depois disso, era-lhe possível, no levantar de um novo dia, vislumbrar Auroras. 


\section{REFERÊNCIAS}

ARENDT, Hannah. Ação. Trad. Roberto Raposo. In: A condição humana. Rio de Janeiro: Forense Universitária, 2005.

BENJAMIN, Walter. O narrador. Observações acerca da obra de Nicolau Leskov. In: BENJAMIN et al. Os pensadores. São Paulo: abril Cultural, 1983.

DALBOSCO, Jocilei. A representação dos contadores de histórias em Sagarana. Passo Fundo: Universidade de Passo Fundo, 2006.

GINZBURG, Jaime. A interpretação do rastro em Walter Benjamin. In: Walter Benjamin: rastro, aura e história. Organizadores: Sabrina Sedlmayer, Jaime Guinzburg. Belo Horizonte: Editora UFMG, 2012.

MASSAUD, Moisés. Dicionário de termos literários. São Paulo: Cultrix, 1975.

ROSA, João Guimarães. Grande Sertão: Veredas. 19. ed. Rio de Janeiro: Nova Fronteira, 2001. 